\title{
Diversity, antimicrobial activity, and susceptibility of culturable soil actinobacteria isolated from Sichang Island
}

\author{
Wongsakorn Phongsopitanun $^{\mathrm{a}, *}$, Paranee Sripreechasak ${ }^{\mathrm{b}}$, Ek Sangvichien ${ }^{\mathrm{c}}$, Somboon Tanasupawat \\ a Department of Biochemistry and Microbiology, Faculty of Pharmaceutical Sciences, Chulalongkorn \\ University, Bangkok 10330 Thailand \\ b Department of Biotechnology, Faculty of Science, Burapha University, Chonburi 20131 Thailand \\ c Department of Biology, Faculty of Science, Ramkhamhaeng University, Bangkok 10240 Thailand
}

*Corresponding author, e-mail: Wongsakorn.p@chula.ac.th

Received 16 Apr 2021

Accepted 26 Jul 2021

\begin{abstract}
Actinobacteria are a promising source of novel antibiotics. The study of diverse actinobacteria from Sichang Island may lead to a discovery of new microbes with pharmaceutical applications. Some actinobacteria, especially those in the genus Nocardia, can cause infection in humans and animals. A total of 55 actinobacteria were isolated from six soil samples collected from Sichang Island, Chonburi Province, Thailand. Based on the morphological characteristics and 16S rRNA gene analysis, the actinobacterial isolates were classified into three genera including Streptomyces (32 isolates), Nocardia (22 isolates), and Saccharothrix (1 isolate). Most of the Streptomyces and the Saccharothrix isolates exhibited antimicrobial activity, with none observed among the Nocardia strains. The 16S rRNA gene similarity suggested three strains represented candidates of novel taxa. Moreover, most of the Nocardia were rare environmental species. Antimicrobial susceptibility testing revealed that amoxicillin/clavulanate (2/1), imipenem, and linezolid were active against Nocardia strains, but they were not susceptible to ceftriaxone, cefotaxime, clarithromycin, ciprofloxacin, and trimethoprim/sulfamethoxazole. The susceptibility profiles vary between strains and species.
\end{abstract}

KEYWORDS: actinobacteria, antimicrobial activity, Nocardia, antimicrobial susceptibility, Sichang Island

\section{INTRODUCTION}

Natural products with pharmaceutical applications can be generated by primary and secondary metabolism of living things [1]. Microorganisms, especially actinobacteria, are the primary source of bioactive natural products [2]. The phylum Actinobacteria consisting of Gram-positive high guanine+cytosine $(\mathrm{G}+\mathrm{C})$ filamentous bacteria is one of the most diverse bacterial groups. Actinobacteria have diverse morphologies ranging from the unicellular rods or cocci to filamentous mycelia [3]. The microbes are widely distributed both on land and in aquatic environments. On land, the soil is the main habitat of most actinobacteria. One gram of soil can contain $10^{6}$ to $10^{9} \mathrm{CFU}$ of actinobacteria [4]. Some actinobacteria are symbiotic with other creatures such as marine sponges and corals as well as plants and lichens $[5,6]$. Different habitats affect the metabolic diversity of the microbes, leading to the production of various types of secondary metabolites.

Actinobacteria, especially genus Streptomyces, are an essential source for antibiotic discovery [7]. Their chemically bioactive secondary metabolites are diverse. To date, some 12000 bioactive compounds have been produced by actinobacteria, and two-thirds of the known antibiotics are produced by members of the genus Streptomyces. Actinobacteria also produce many anticancer and antifungal compounds, antiviral agents, antiparasitics, insecticides, herbicides, immunosuppressants, and therapeutic enzymes [8].

Most actinobacteria are producers of valuable bioactive compounds; however, some actinobacterial genera, especially Nocardia species, can cause a disease called "nocardiosis" in patients with cellmediated immunosuppressive conditions as well as in immunocompetent patients [9]. Some actinobacterial species, such as Actinomadura madurae and Streptomyces somaliensis, also cause mycetoma, a chronic granulomatous infection, presenting as subcutaneous tissue swelling of the affected area, nodule formation, and drainage through sinus tracts [10]. Consequently, susceptibility testing of 
these actinobacterial pathogens will assist in disease treatment.

Sichang Island is the smallest district of Thailand and located in the Gulf of Thailand. The island is $12 \mathrm{~km}$ from the mainland of Chonburi Province and consists mainly of rocks, mountains, and crags. Soil from the island was expected to contain promising antibiotic producers and novel actinobacterial taxa.

This study focused on the isolation and antimicrobial activities screening of actinobacteria in soil samples collected from Sichang Island, Chonburi Province, Thailand. The antimicrobial susceptibilities of Nocardia isolates were also determined.

\section{MATERIALS AND METHODS}

\section{Sample collection and isolation of actinobacteria}

Soil samples were collected from six locations on Sichang Island, Chonburi Province, Thailand during the month of February 2017 (Fig. S1). The samples were preserved at $4{ }^{\circ} \mathrm{C}$ before transporting to the laboratory. Actinobacteria were isolated following the standard serial dilution methods using humic acid vitamin (HV) agar supplemented with nalidixic acid $(50 \mu \mathrm{g} / \mathrm{ml})$ and cycloheximide $(25 \mu \mathrm{g} / \mathrm{ml})$ [11]. The isolate plates were incubated at $30^{\circ} \mathrm{C}$ for 14 days. Colonies of actinobacteria were observed under light microscope and selected for further purification on yeast extract-malt extract (ISP2) agar (yeast extract $4 \mathrm{~g}$, malt extract $10 \mathrm{~g}$, glucose $4 \mathrm{~g}, \mathrm{pH} 7.0-7.2$, added water up to 11 ). Pure cultures of actinobacteria were maintained on ISP2 agar at $30^{\circ} \mathrm{C}$.

\section{$16 S$ rRNA gene and phylogenetic analyses}

Actinobacterial DNA was extracted from mycelia, obtained from the culture grown in yeast-dextrose broth at $30^{\circ} \mathrm{C}$ for $4-7$ days, using a DNA extraction kit (Purelink ${ }^{\mathrm{TM}}$ ). The 16S rRNA gene amplification was carried out using primers $20 \mathrm{~F}$ (5'-GAGTTTGATCCTGGCTCAG-3') and 1500R ( $5^{\prime}$ GTTACCTTGTTACGACTT-3') [12]. The PCR products were purified using a Gel/PCR kit (Geneaid). Nucleotide sequencing of the PCR products was carried out using universal primers [13] (Macrogen, Seoul, Korea). BLASTN analysis of the 16S rRNA sequences was performed according to the EzBioCloud webpage (https://www.ezbiocloud. net) [14]. Sequences of all the actinobacterial isolates were aligned with selected sequences obtained from the GenBank/EMBLDDBJ database using BioEdit (Ibis Biosciences). A phylogenetic tree based on maximum likelihood was constructed using MEGA 7.0 [15] with all gaps eliminated before the calculation. The confidence values of tree nodes were evaluated using the bootstrap resampling method based on 1000 replications [16].

\section{Antimicrobial screening}

A cross-streak method was used to perform antimicrobial activity screening [17]. The actinobacteria were streaked on one side of the ISP2 agar plates and incubated at $30^{\circ} \mathrm{C}$ for 14 days. Then, the tested microorganisms: Bacillus subtilis ATCC 6633, Косuria rhizophila ATCC 4341, Staphylococcus aureus ATCC 25923, Pseudomonas aeruginosa ATCC 27853, Escherichia coli ATCC 25922, and Candida albicans ATCC 10231 were inoculated on the plates by a single streak perpendicular to the actinobacteria and incubated at $37^{\circ} \mathrm{C}$ for $24 \mathrm{~h}$. Finally, the inhibition area was recorded.

\section{Antimicrobial susceptibility of Nocardia isolates}

Susceptibility testing was performed by the Etest method using Ezy MIC $^{\text {TM }}$ strips (Himedia) on Mueller-Hinton (MH) agar plates inoculated by swabbing method. Minimum inhibitory concentrations (MICs) and resistance breakpoint were determined according to the Clinical and Laboratory Standards Institute (CLSI) criteria (M24-A2) [18]. All Nocardia isolates obtained were tested with ten antibiotics: amikacin, amoxicillin/clavulanate $(2 / 1)$, ceftriaxone, cefotaxime, ciprofloxacin, clarithromycin, imipenem, linezolid, minocycline, and trimethoprim/sulfamethoxazole. The MIC values were recorded after incubating the plates at $30^{\circ} \mathrm{C}$ for 3 days.

\section{RESULTS AND DISCUSSION}

\section{Identification and antimicrobial activity}

Six rocky soil samples were collected from Sichang Island. Density of culturable actinobacteria in the soil samples ranged from $5 \times 10^{5}$ to $1 \times 10^{6} \mathrm{CFU} / \mathrm{g}$, and 55 actinobacteria were isolated (Table 1). These bacteria were classified into three genus groups: Streptomyces, Nocardia, and Saccharothrix based on morphological characteristics and 16S rRNA gene analysis. The phylogenetic tree confirmed the classification into these three genera (Figs. 1 and 2).

Group I comprised 32 isolates (Fig. 1). These bacteria produced long-branching filamentous mycelia on the agar. Spiral chains and rectiflexibile type of spore chains were observed on the aerial 


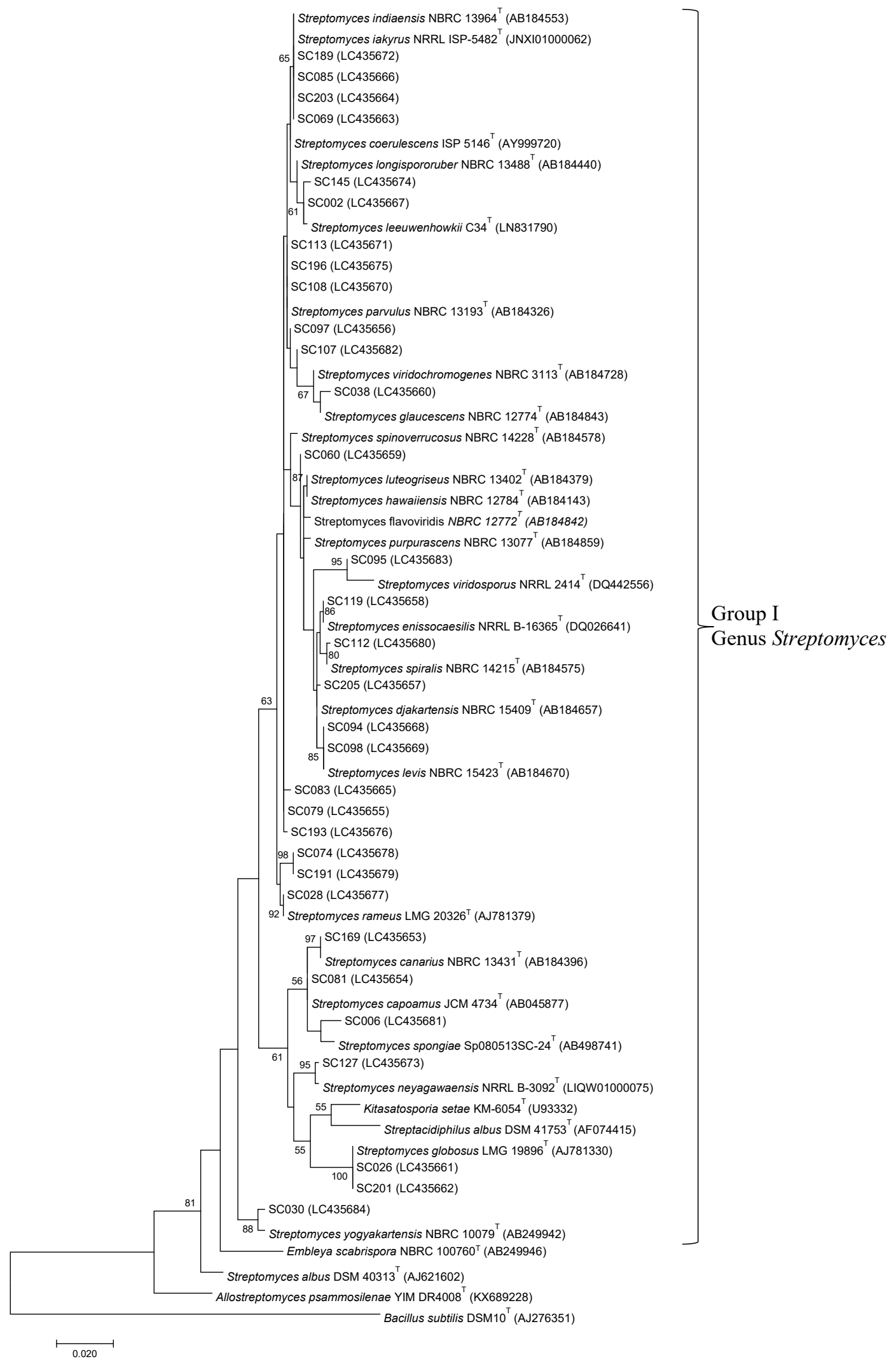

Fig. 1 Phylogenetic tree showing the relationship between actinobacterial isolates in group I and related actinobacterial species. Bacillus subtilis DSM10 ${ }^{\mathrm{T}}$. was used as the outgroup. 


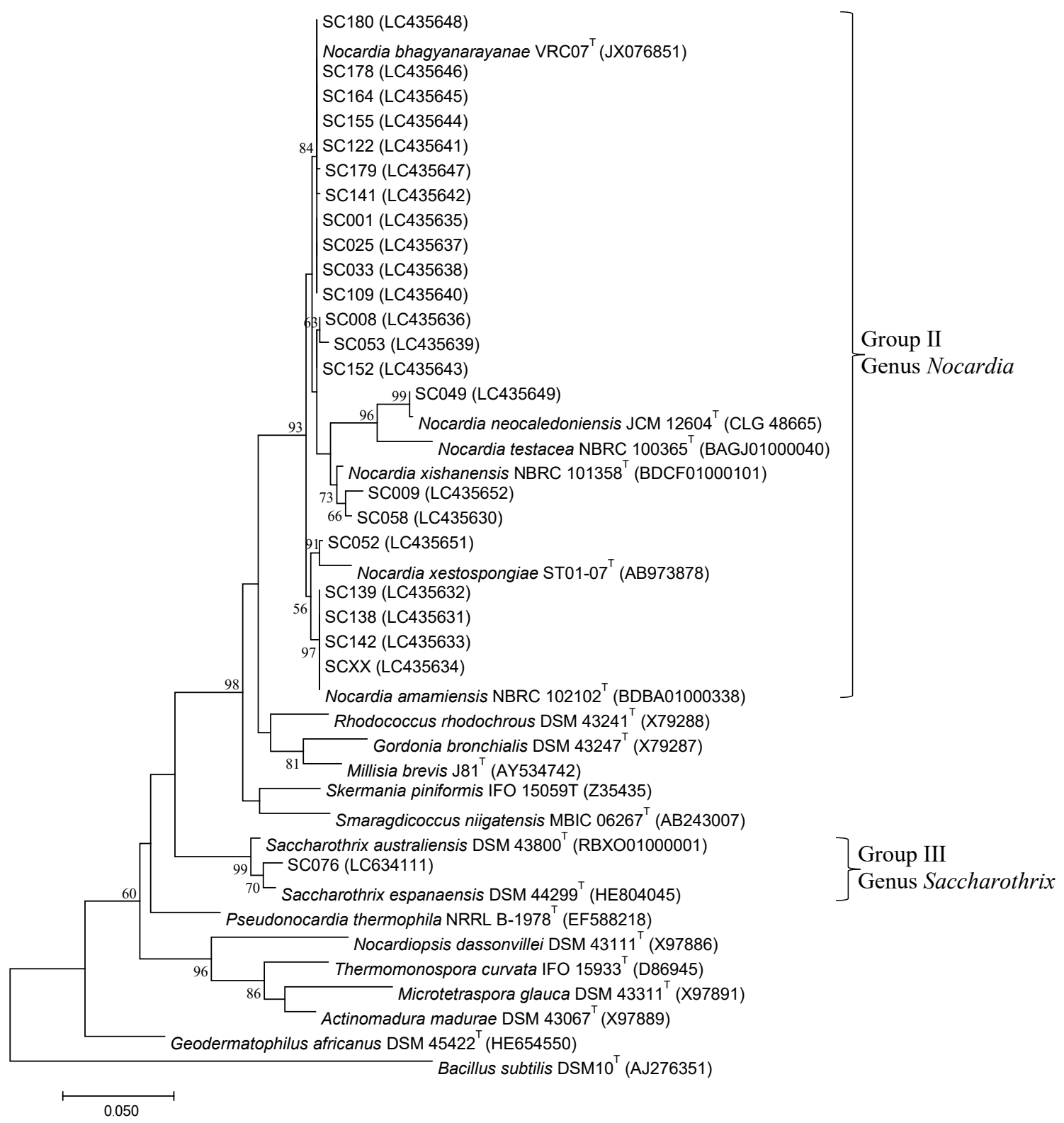

Fig. 2 Phylogenetic tree showing the relationship of the actinobacterial isolates in group II, group III, and related type strains. Bacillus subtilis DSM10 ${ }^{\mathrm{T}}$ was used as the outgroup.

mycelia. The representative isolate, SC095, produced a white to light gray aerial mass that could be differentiated from the spiral spore chain (Fig. S2). This spiral chain resembled characteristics of the genus Streptomyces. Based on the 16S rRNA gene analysis, these bacteria represented the highest similarity to those of the genus Streptomyces. Furthermore, members in this group were classified into 25 different closely related species (Table S1) of which $100 \%$ sequence similarity was observed with the 4 species:
S. enissocaesilis, S. globosus, S. levis, and S. rameus.

Group II consisted of 22 isolates (Fig. 2). These bacteria produced white to pale cream aerial mycelia and pale orange substrate mycelia. Based on microscopic observation, branching filaments and fragmented zigzag conformation were observed on the aerial mycelia and substrate mycelia, respectively. The 22 strains did not produce any soluble pigment in the agar. The representative strain of this group, SC052, was also observed showing yellowish white aerial mass and grayish 
Table 1 Number of actinobacterial isolates.

\begin{tabular}{|c|c|c|}
\hline $\begin{array}{l}\text { Sample } \\
\text { no. }\end{array}$ & Isolate no. & $\begin{array}{l}\text { Number of } \\
\text { isolates }\end{array}$ \\
\hline 1 & $\begin{array}{l}\text { SC001, SC008, SC053, SC049, } \\
\text { SC052, SC009, SC097, SC083, } \\
\text { SC085, SC002, SC094, SC113, } \\
\text { SC006, SC107, SC095, SC058 }\end{array}$ & 16 \\
\hline 2 & $\begin{array}{l}\text { SCXX, SC141, SC081, SC079, } \\
\text { SC145, SC074 }\end{array}$ & 6 \\
\hline 3 & $\begin{array}{l}\text { SC060, SC076, SC152, SC155 } \\
\text { SC069 }\end{array}$ & 5 \\
\hline 4 & $\begin{array}{l}\text { SC138, SC139, SC025, SC033, } \\
\text { SC109, SC122, SC119, SC038, } \\
\text { SC026, SC098, SC108, SC127, } \\
\text { SC028, SC112, SC030 }\end{array}$ & 15 \\
\hline 5 & $\begin{array}{l}\text { SC142, SC164, SC178, SC179, } \\
\text { SC180, SC196 }\end{array}$ & 6 \\
\hline \multirow[t]{2}{*}{6} & $\begin{array}{l}\text { SC169, SC203, SC205, SC189, } \\
\text { SC193, SC191, SC201 }\end{array}$ & 7 \\
\hline & Total number of isolates & 55 \\
\hline
\end{tabular}

yellow substrate mycelia with fragmented substrate mycelia (Fig. S2). These characteristics were similar to members of the genus Nocardia. Based on the BLAST result of the 16S rRNA gene, actinobacteria in group 1 showed highest similarity with members of the genus Nocardia. These data were used to classify the actinobacteria in this group into six different closely related species as Nocardia amamiensis, Nocardia bhayanarayanae, Nocardia lijiangensis, Nocardia neocaledoniensis, Nocardia xestospongiae and Nocardia xishaensis (Table S1). Among these, isolates related to $N$. bhayanarayanae were the most frequent and five out of the six soil samples contained $N$. bhayanarayanae (Table 1 ).

Group III contained one isolate as SC076. This strain produced white aerial mycelia and paleyellow green substrate mycelia. No pigment was observed on ISP3 agar. SC076 showed the closest 16S rRNA gene similarity (98.58\%) to Saccharothrix australiensis DSM $43800^{\mathrm{T}}$.

In 2014, Kim et al suggested that a value of 98.65\% 16S rRNA gene sequence similarity could be used as the threshold for differentiating two bacterial species [19]. In this study, three isolates including SC095, SC076, and SC052 showed 16S rRNA gene similarity lower than $98.65 \%$, indicating that these three strains were candidates of novel actinobacterial taxa.

All the Nocardia isolates showed no antimi- crobial activity against the tested microorganisms, while the 22 isolates of Streptomyces did. Besides, 21 Streptomyces isolates inhibited Gram-positive bacteria; but only three and seven isolates inhibited Gram-negative bacteria and yeast, respectively. Members of the Streptomyces genus that showed antimicrobial activity included S. coerulescens SC097, S. djakartensis SC205, S. enissocaesilis SC119, S. globosus SC201, S. hawaiiensis SC069, S. iakyrus SC203, S. indiaensis SC083, S. levis strains SC094 and SC098, S. longispororuber strains SC108 and SC113, S. luteogriseus SC189, S. neyagawaensis SC127, S. parvulus strains SC145 and SC196, S. purpurascens SC193, S. spinoverrucosus strains SC074 and SC191, S. spiralis SC112, S. viridochromogenes SC107, and S. viridosporus SC095. Interestingly, one candidate as the novel Saccharothrix SC076 showed potent antimicrobial activity against $K$. rhizophila, B. subtilis, S. aureus, E. coli, and C. albicans. Results in Table S1 indicated that strain SC076 showed broad-spectrum activity.

The Streptomyces genus is the largest antibiotic producer. However, since the 1970s, a number of antimicrobial compounds reported annually from this genus have substantially declined. Streptomyces is a common soil microorganism, and its isolation from soil over several decades leads to continued reisolation of the same species. Consequently, obtaining novel compounds is difficult, and results often yield previously known compounds [20]. To solve this problem, several studies suggested that unexplored habitats offered promising sources of novel antibiotic producer. In 2017, Yun et al observed the diversity of soil actinobacteria collected from Ulleung Island, Korea. This Island was expected to yield unique microorganisms. They isolated 34 actinobacteria comprising Streptomyces (16 isolates), Isoptericola (5 isolates), Rhodococcus (4 isolates), Agromyces (3 isolates), Micrococcus (2 isolates), Arthrobacter (1 isolate), Williamsia (1 isolate), Microbacterium (1 isolate), and Oerskovia (1 isolate). Based on the phylogenetic tree, some of these actinobacteria represented candidates for novel species [21]. Later, in 2019, Sottorff et al analysed soil samples collected from Easter Island, Chile, and the samples comprised many novel candidate actinobacteria. A total of 163 actinobacterial isolates with 72 different phylotypes and 20 genera were found. The most abundant genera were $M i-$ cromonospora, Streptomyces, Salinispora, and Dietzia. Interestingly, $45 \%$ of the actinobacteria from Easter Island showed a high degree of novelty as possible new taxa [22]. The results supported the 
assumption that island soil harbors new actinobacterial species that might show a promise for further drug development.

\section{Antimicrobial susceptibility of Nocardia isolates}

The antimicrobial susceptibility of six closely related species of Nocardia including $N$. amamiensis $(n=4), N$. bhagyanarayanae $(n=11), N$. neocaledoniensis $(n=1), N$. xestospongiae $(n=1)$, $N$. lijiangensis $(n=1)$, and $N$. xishanensis $(n=1)$ were determined using Etest. All isolates were found susceptible to imipenem and linezolid. The antimicrobial susceptibility profiles revealed that $N$. amamiensis was not susceptible to ciprofloxacin, ceftriaxone, and cefotaxime. Most strains of this species were resistant to clarithromycin $(50 \%)$ and trimethoprim-sulfamethoxazole (75\%) and susceptible to amikacin, minocycline, imipenem, linezolid, and amoxicillin/clavulanate (2/1). N. bhagyanarayanae was the most prevalent species obtained from Sichang Island. The results indicated that more than $90 \%$ of $N$. bhagyanarayanae was not susceptible to clarithromycin, ceftriaxone, cefotaxime, ciprofloxacin, and trimethoprimsulfamethoxazole but susceptible to amikacin, linezolid and imipenem; while $27 \%$ were resistant to amikacin, and $73 \%$ showed intermediate resistant to minocycline.

Individual isolate of $N$. neocaledoniensis, $N$. lijiangensis, and $N$. xishanensis was obtained in this study. These strains were susceptible to amikacin, minocycline, imipenem, linezolid, and amoxycillin/clavulanate (2/1); except $N$. xishanensis $(n=1)$ that showed intermediate resistance to amoxycillin/clavulanate (2/1) (Table 2).

Strain SC052 showed a $97.8 \%$ similarity of the 16S rRNA gene. This strain should be a candidate of novel taxa. It was susceptible to amikacin, minocycline, imipenem, linezolid, and amoxicillin/clavulanate; but resistant to ciprofloxacin, ceftriaxone, cefotaxime, and trimethoprim-sulfamethoxazole (Table 2).

Nocardiosis is a common opportunistic infection found in immunocompromised patients. In 2005, Mootsikapun et al presented a review of nocardiosis cases from 1996 to 2001 in Srinagarind Hospital, Thailand. Data from 70 cases revealed that $80 \%$ of patients were male with mean age of $39.7 \pm 14.9$ years. The common diagnosis was a pleuropulmonary infection, followed by skin and soft tissue infection. In their study, $57.9 \%$ of the Nocardia isolates were resistant to trimethoprimsulfamethoxazole [23]. Valdezate et al reported the antimicrobial susceptibility of Nocardia species in Spain. Most Nocardia strains were isolated from respiratory tract. They identified $N$. cyriacigeorgica, $N$. nova, $N$. abscessus, $N$. farcinica, $N$. carnea, $N$. brasiliensis, $N$. otitidiscaviarum, $N$. flavorosea, $N$. rhamnosiphila, and $N$. transvalensis as active species against linezolid and amikacin [24]. In 2019, Lebeaux et al (in France) analyzed 793 Nocardia isolates collected between 2010 and 2015. These Nocardia were mainly isolated from lungs and comprised N. farcinica, N. abcessus complex, and $N$. nova complex. Active antibiotics against these species were linezolid, amikacin, trimethoprim-sulfamethoxazole, minocycline, and imipenem. $N$. farcinica showed a high rate $(73 \%)$ of resistance to cefotaxime, while approximately $5 \%$ of $N$. cyriacigeorgica and $N$. abscessus were resistant to cefotaxime [25].

$N$. bhagyanarayanae and $N$. amamiensis were the most frequent species found on Sichang Island. Infection caused by $N$. amamiensis is rare, with only two ocular and two pulmonary infections previously reported [26, 27]. In 2016, MartinezGamboa et al reported pulmonary infection caused by $N$. amamiensis in Mexico. The strain was susceptible to trimethoprim-sulfamethoxazole, amoxicillin/clavulanic acid, imipenem, and amikacin [27]. Reddy et al reported two strains of $N$. amamiensis isolated from ocular infection [26]. Both strains were susceptible to tobramycin and amikacin but not susceptible to azithromycin and clarithromycin, while one isolate was not susceptible to gatifloxacin and ciprofloxacin. One strain of $N$. bhagyanarayanae was also reported for Nocardia keratitis [28].

$N$. neocaledoniensis is an uncommon cause of human infection and rarely documented for skin, soft tissue, and ocular infection [26, 29]. In 2020, the first fatal bacteremia case due to $N$. neocaledoniensis was reported [30], while an outbreak of $N$. neocaledoniensis mastitis in an Italian dairy herd was reported in 2008 [31]. At the time of reporting the present study, there has been no case report for both $N$. lijiangensis and $N$. xishanensis infections.

\section{CONCLUSION}

The most frequent taxa found as culturable soil actinobacteria of Sichang Island comprised the genera Streptomyces and Nocardia. Most Streptomyces strains showed antimicrobial activity. Three isolates from this study were identified as candidates of novel taxa. This number suggested that soil from the island was a promising source of novel acti- 


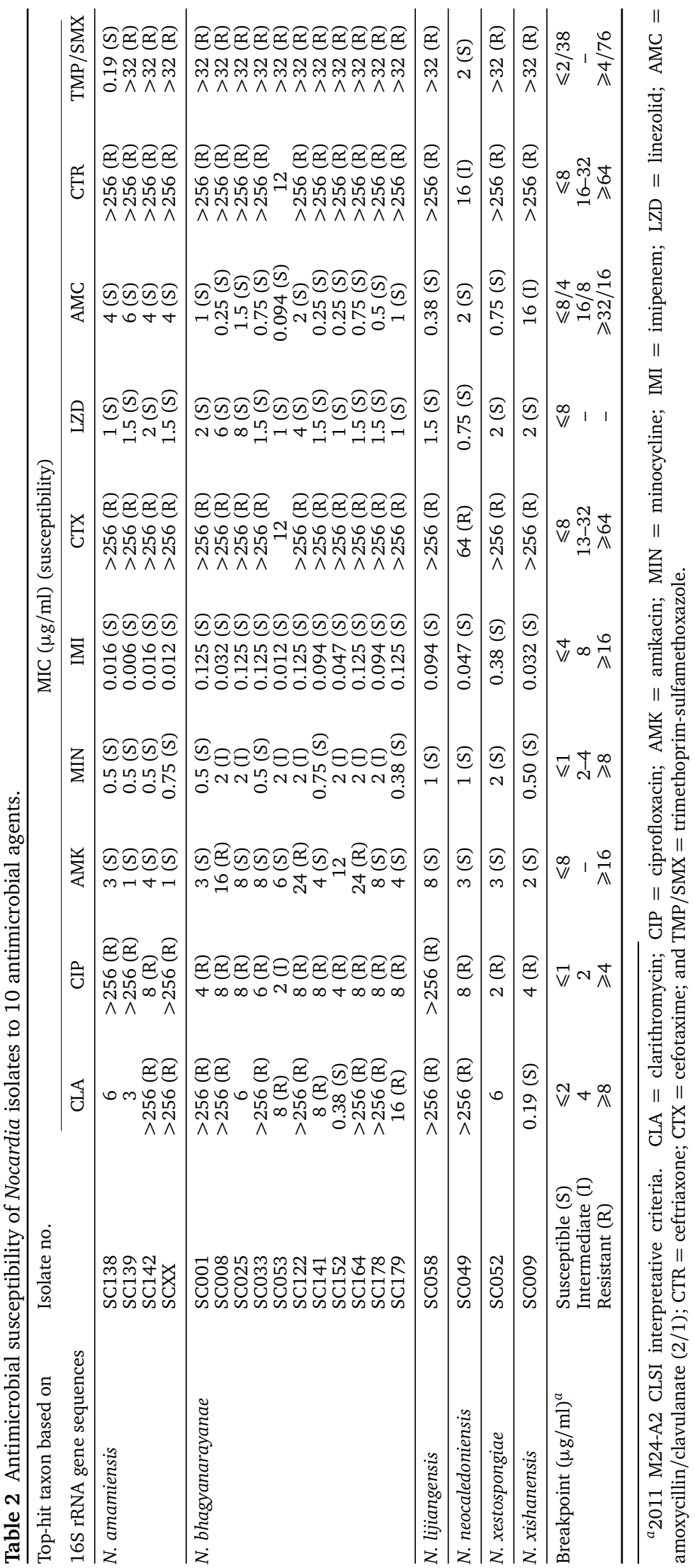


nobacteria. Many Nocardia species were isolated in this study, but these species are rarely reported as causing infection in humans. Antimicrobial susceptibility testing indicated that most Nocardia strains were susceptible to amoxicillin/clavulanate, imipenem, linezolid, and amikacin but not susceptible to ciprofloxacin, ceftriaxone, cefotaxime, and trimethoprim/sulfamethoxazole. However, the susceptibility profiles varied between strains and species.

\section{Appendix A. Supplementary data}

Supplementary data associated with this article can be found at http://dx.doi.org/10.2306/ scienceasia1513-1874.2021.088.

Acknowledgements: This work was supported by the Research and Development Institute of Ramkhamhaeng University and the Grants for Development of New Faculty Staffs, Ratchadaphiseksomphot Endowment Fund, Chulalongkorn University (DNS 63_079_33_005_1).

\section{REFERENCES}

1. Demain AL, Sanchez S (2009) Microbial drug discovery: 80 years of progress. J Antibiot 62, 5-16.

2. Matsumoto A, Takahashi Y (2017) Endophytic actinomycetes: promising source of novel bioactive compounds. J Antibiot 70, 514-519.

3. van Bergeijk DA, Terlouw BR, Medema $\mathrm{MH}$, van Wezel GP (2020) Ecology and genomics of Actinobacteria: new concepts for natural product discovery. Nat Rev Microbiol 18, 546-558.

4. Barka EA, Vatsa P, Sanchez L, Gaveau-Vaillant N, Jacquard C, Meier-Kolthoff JP, Klenk HP, Clément C, et al (2015) Taxonomy, physiology, and natural products of Actinobacteria. Microbiol Mol Biol Rev 80, $1-43$.

5. Jiang S, Sun W, Chen M, Dai S, Zhang L, Liu Y, Lee KJ, Li X (2007) Diversity of culturable actinobacteria isolated from marine sponge Haliclona sp. Antonie Van Leeuwenhoek 92, 405-416.

6. Phongsopitanun W, Sripreechasak P, Rueangsawang K, Panyawut R, Pittayakhajonwut P, Tanasupawat S (2020) Diversity and antimicrobial activity of culturable endophytic actinobacteria associated with Acanthaceae plants. ScienceAsia 46, 288-296.

7. Genilloud O (2017) Actinomycetes: still a source of novel antibiotics. Nat Prod Rep 34, 1203-1232.

8. Berdy J (2005) Bioactive microbial metabolites. $J$ Antibiot 58, 1-26.

9. Wilson JW (2012) Nocardiosis: updates and clinical overview. Mayo Clin Proc 87, 403-407.

10. Lichon V, Khachemoune A (2006) Mycetoma: a review. Am J Clin Dermatol 7, 315-321.
11. Hayakwa M, Nonomura H (1987) Humic acidvitamin agar, a new medium for selective isolation of soil actinomycetes. $J$ Ferment Technol 65, 501-509.

12. Suriyachadkun C, Chunhametha S, Thawai C, Tamura T, Potacharoen W, Kirtikara K, Sanglier JJ (2009) Planotetraspora thailandica sp. nov., isolated from soil in Thailand. Int J Syst Evol Microbiol 59, 992-997.

13. Lane DJ (1991) 16S/23S rRNAsequencing. In: Stackebrandt E, Goodfellow M (eds) Nucleic Acid Techniques in Bacterial Systematics, Wiley, Chichester, pp 115-148.

14. Yoon SH, Ha SM, Kwon S, Lim J, Kim Y, Seo H, Chun J (2017) Introducing EzBioCloud: a taxonomically united database of $16 \mathrm{~S}$ rRNA gene sequences and whole-genome assemblies. Int J Syst Evol Microbiol 67, 1613-1617.

15. Kumar S, Stecher G, Tamura K (2016) MEGA7: molecular evolutionary genetics analysis version 7.0 for bigger datasets. Mol Biol Evol 33, 1870-1874.

16. Felsenstein J (1985) Confidence limits on phylogenies: an approach using the bootstrap. Evolution 39, 783-791.

17. Saravana Kumar P, Duraipandiyan V, Ignacimuthu S (2014) Isolation, screening and partial purification of antimicrobial antibiotics from soil Streptomyces sp. SCA 7. Kaohsiung J Med Sci 30, 435-446.

18. Kim M, Oh HS, Park SC, Chun J (2014) Towards a taxonomic coherence between average nucleotide identity and 16S rRNA gene sequence similarity for species demarcation of prokaryotes. Int $J$ Syst Evol Microbiol 64, 346-351.

19. CLSI (2011) Susceptibility Testing of Mycobacteria, Nocardiae, and other Aerobic Actinomycetes; Approved Standard, 2nd edn, CLSI document M24-A2, Clinical and Laboratory Standards Institute, Wayne, PA.

20. Watve MG, Tickoo R, Jog MM, Bhole BD (2001) How many antibiotics are produced by the genus Streptomyces? Arch Microbiol 176, 386-390.

21. Yun B, Roh SG, Kim SB (2017) Diversity and physiological properties of soil actinobacteria in Ulleung Island. Korean J Microbiol 53, 242-250.

22. Sottorff I, Wiese J, Imhoff JF (2019) High diversity and novelty of Actinobacteria isolated from the coastal zone of the geographically remote young volcanic Easter Island. Chile Int Microbiol 22, 377-390.

23. Mootsikapun P, Intarapoka B, Liawnoraset W (2005) Nocardiosis in srinagarind hospital, Thailand: review of 70 cases from 1996-2001. Int J Infect Dis 9, 154-158.

24. Valdezate S, Garrido N, Carrasco G, Medina-Pascual MJ, Villalón P, Navarro AM, Saéz-Nieto JA (2017) Epidemiology and susceptibility to antimicrobial agents of the main Nocardia species in Spain. $J$ Antimicrob Chemother 72, 754-761.

25. Lebeaux D, Bergeron E, Berthet J, Djadi-Prat J, Mouniée D, Boiron P, Lortholary O, Rodriguez-Nava 
V (2019) Antibiotic susceptibility testing and species identification of Nocardia isolates: a retrospective analysis of data from a French expert laboratory, 2010-2015. Clin Microbiol Infect 25, 489-495.

26. Reddy AK, Garg P, Kaur I (2010) Speciation and susceptibility of Nocardia isolated from ocular infections. Clin Microbiol Infect 16, 1168-1171.

27. Martinez-Gamboa A, Cervera-Hernandez ME, TorresGonzalez P, Rangel-Cordero A, Ponce-de-Leon A, Sifuentes-Osornio J (2016) First case of Nocardia amamiensis pulmonary infection in Mexico. New Microbes New Infect 16, 1-2.

28. Andre E, Durkee HA, Arboleda A, Maestre J, Miller D, Parel JA (2020) Characterization of South Florida Nocardia keratitis: trends, risk factors, susceptibility and response to photodynamic therapy. Invest Ophthalmol Vis Sci 61, ID 4906.

29. McGhie T, Fader R, Carpenter J, Brown-Elliott BA, Vasireddy R, Wallace RJ Jr (2012) Nocardia neocaledoniensis as a cause of skin and soft tissue infection. J Clin Microbiol 50, 3139-3140.

30. Regueme A, Vachee A, Duployez C, Petit AE, Coulon P, Wallet F, Loiez C (2020) First case of fatal bacteremia due to Nocardia neocaledoniensis. IDCases $\mathbf{2 2}$, e00934.

31. Pisoni G, Locatelli C, Alborali L, Rosignoli C, Allodi S, Riccaboni P, Grieco V, Moroni P (2008) Short communication: outbreak of Nocardia neocaledoniensis mastitis in an Italian dairy herd. J Dairy Sci 91, 136-139. 


\section{Appendix A. Supplementary data}

Table S1 Closest BLASTN matches for the 16S rDNA sequence and antimicrobial activity of the actinobacterial isolates.

\begin{tabular}{|c|c|c|c|c|c|c|c|c|c|c|c|}
\hline \multirow{2}{*}{ No. } & \multirow{2}{*}{ Isolate no. } & \multirow{2}{*}{ Top-hit taxon } & \multirow{2}{*}{$\begin{array}{c}\text { Similarity } \\
(\%)\end{array}$} & \multirow{2}{*}{$\begin{array}{c}\text { Length } \\
\text { (nt) }\end{array}$} & \multirow{2}{*}{$\begin{array}{c}\text { Accession } \\
\text { no. }\end{array}$} & \multicolumn{6}{|c|}{ Antimicrobial activity ${ }^{\dagger}$} \\
\hline & & & & & & S & B & $\mathrm{K}$ & E & $\mathrm{P}$ & $\mathrm{C}$ \\
\hline 1 & SC138 & Nocardia amamiensis NBRC $102102^{\mathrm{T}}$ & 99.93 & 1462 & LC435631 & - & - & - & - & - & - \\
\hline 2 & SC139 & Nocardia amamiensis NBRC $102102^{\mathrm{T}}$ & 100 & 1454 & LC435632 & - & - & - & - & - & - \\
\hline 3 & SC142 & Nocardia amamiensis NBRC $102102^{\mathrm{T}}$ & 99.35 & 1401 & LC435633 & - & - & - & - & - & - \\
\hline 4 & SCXX & Nocardia amamiensis NBRC $102102^{\mathrm{T}}$ & 100 & 1457 & LC435634 & - & - & - & - & - & - \\
\hline 5 & SC001 & Nocardia bhagyanarayanae $\mathrm{VRC} 7^{\mathrm{T}}$ & 99.44 & 1466 & LC435635 & - & - & - & - & - & - \\
\hline 6 & SC008 & Nocardia bhagyanarayanae VRC07 & 99.58 & 1460 & LC435636 & _- & _- & - & - & - & - \\
\hline 7 & SC025 & Nocardia bhagyanarayanae VRC07 & 100 & 1398 & LC435637 & _- & _- & _- & _- & - & - \\
\hline 8 & SC033 & Nocardia bhagyanarayanae VRC07 & 100 & 1400 & LC435638 & - & - & - & _- & - & - \\
\hline 9 & SC053 & Nocardia bhagyanarayanae VRC07 & 99.44 & 1466 & LC435639 & _- & _- & _- & _- & - & - \\
\hline 10 & SC109 & Nocardia bhagyanarayanae VRC0 $7^{\mathrm{T}}$ & 100 & 1414 & LC435640 & - & - & - & - & - & - \\
\hline 11 & SC122 & Nocardia bhagyanarayanae VRC07 & 100 & 1400 & LC435641 & - & - & - & - & - & - \\
\hline 12 & SC141 & Nocardia bhagyanarayanae VRC0 $7^{\mathrm{T}}$ & 99.93 & 1394 & LC435642 & - & - & - & - & - & - \\
\hline 13 & SC152 & Nocardia bhagyanarayanae VRC07 & 99.72 & 1452 & LC435643 & - & - & - & - & - & - \\
\hline 14 & SC155 & Nocardia bhagyanarayanae VRC0 $7^{\mathrm{T}}$ & 100 & 1396 & LC435644 & - & - & - & - & - & - \\
\hline 15 & SC164 & Nocardia bhagyanarayanae VRC0 ${ }^{\mathrm{T}}$ & 99.79 & 1485 & LC435645 & - & - & - & - & - & - \\
\hline 16 & SC178 & Nocardia bhagyanarayanae VRC0 $7^{\mathrm{T}}$ & 100 & 1427 & LC435646 & - & - & - & - & - & - \\
\hline 17 & SC179 & Nocardia bhagyanarayanae $\mathrm{VRC}^{\mathrm{T}}{ }^{\mathrm{T}}$ & 99.90 & 1468 & LC435647 & _- & _- & - & _- & - & - \\
\hline 18 & SC180 & Nocardia bhagyanarayanae $\mathrm{VRC}^{\mathrm{T}}{ }^{\mathrm{T}}$ & 100 & 1463 & LC435648 & - & - & - & - & - & - \\
\hline 19 & SC058 & Nocardia lijiangensis NBRC $108240^{\mathrm{T}}$ & 99.75 & 834 & LC435630 & - & - & - & - & - & - \\
\hline 20 & SC049 & Nocardia neocaledoniensis JCM $12604^{\mathrm{T}}$ & 99.93 & 1388 & LC435649 & - & - & - & - & - & - \\
\hline 21 & SC052 & Nocardia xestospongiae ST01-07 ${ }^{\mathrm{T}}$ & 97.84 & 1415 & LC435651 & - & - & - & - & - & - \\
\hline 22 & SC009 & xishanensis NBRC $101358^{\mathrm{T}}$ & 99.17 & 1466 & LC435652 & - & - & - & - & - & - \\
\hline 23 & SC169 & Streptomyces canarius NBRC $13431^{\mathrm{T}}$ & 99.20 & 1461 & LC435653 & - & - & - & - & - & - \\
\hline 24 & SC081 & Streptomyces capoamus JCM $4734^{\mathrm{T}}$ & 99.65 & 1469 & LC435654 & - & - & - & - & - & - \\
\hline 25 & SC079 & Streptomyces coerulescens ISP $5146^{\mathrm{T}}$ & 99.77 & 1288 & LC435655 & _- & _- & _- & _- & - & - \\
\hline 26 & SC097 & Streptomyces coerulescens ISP $5146^{\mathrm{T}}$ & 99.44 & 1474 & LC435656 & \pm & \pm & + & - & - & - \\
\hline 27 & SC205 & Streptomyces djakartensis NBRC $15409^{\mathrm{T}}$ & 99.71 & 1423 & LC435657 & ++ & ++ & ++ & & & \\
\hline 28 & SC119 & Streptomyces enissocaesilis NRRL-B $16365^{\mathrm{T}}$ & 100 & 1469 & LC435658 & ++ & ++ & ++ & ++ & + & + \\
\hline 29 & SC060 & Streptomyces flavoviridis NBRC $12772^{\mathrm{T}}$ & 99.17 & 1471 & LC435659 & - & - & - & - & - & - \\
\hline 30 & SC038 & Streptomyces glaucescens NBRC $12774^{\mathrm{T}}$ & 99.61 & 1325 & LC435660 & - & - & - & - & - & - \\
\hline 31 & SC026 & Streptomyces globosus LMG $19896^{\mathrm{T}}$ & 100 & 1445 & LC435661 & - & - & - & - & - & - \\
\hline 32 & SC201 & globosus LMG $19896^{\mathrm{T}}$ & 100 & 1047 & LC435662 & - & \pm & - & - & - & - \\
\hline 33 & SC069 & Streptomyces hawaiiensis NBRC $12784^{\mathrm{T}}$ & 99.52 & 1471 & LC435663 & ++ & ++ & ++ & - & - & - \\
\hline 34 & SC203 & Streptomyces iakyrus NRRL ISP-5482 ${ }^{\mathrm{T}}$ & 99.86 & 1402 & LC435664 & + & ++ & + & - & - & \pm \\
\hline 35 & SC083 & Streptomyces indiaensis NBRC $13964^{\mathrm{T}}$ & 99.31 & 1486 & LC435665 & ++ & ++ & ++ & - & - & + \\
\hline 36 & SC085 & Streptomyces indiaensis NBRC $13964^{\mathrm{T}}$ & 99.93 & 1473 & LC435666 & - & ++ & \pm & - & - & - \\
\hline 37 & SC002 & Streptomyces leeuwenhoekii C34 & 99.38 & 1461 & LC435667 & - & - & - & - & - & - \\
\hline 38 & SC094 & Streptomyces levis NBRC $15423^{\mathrm{T}}$ & 100 & 1410 & LC435668 & \pm & + & ++ & - & - & \pm \\
\hline 39 & SC098 & Streptomyces levis NBRC $15423^{\mathrm{T}}$ & 100 & 1459 & LC435669 & + & + & ++ & - & - & \pm \\
\hline 40 & SC108 & Streptomyces longispororuber NBRC $13488^{\mathrm{T}}$ & 99.44 & 1468 & LC435670 & - & - & - & - & \pm & - \\
\hline 41 & SC113 & Streptomyces longispororuber NBRC $13488^{\mathrm{T}}$ & 99.43 & 1452 & LC435671 & - & \pm & - & - & - & - \\
\hline 42 & SC189 & yces luteogriseus NBRC $13402^{\mathrm{T}}$ & 99.65 & 1457 & LC435672 & ++ & ++ & ++ & - & - & - \\
\hline 43 & SC127 & Streptomyces neyagawaensis NRRL-B 309 & 99.59 & 1491 & LC435673 & ++ & ++ & ++ & - & - & - \\
\hline 44 & SC145 & Streptomyces parvulus NBRC $13193^{\mathrm{T}}$ & 98.96 & 1455 & LC435674 & - & \pm & - & - & - & ++ \\
\hline 45 & SC196 & Streptomyces parvulus NBRC $13193^{\mathrm{T}}$ & 99.86 & 1467 & LC435675 & ++ & ++ & ++ & - & - & - \\
\hline 46 & SC193 & Streptomyces purpurascens NBRC $13077^{\mathrm{T}}$ & 99.45 & 1472 & LC435676 & ++ & ++ & ++ & - & - & - \\
\hline 47 & SC028 & Streptomyces rameus LMG $20326^{\mathrm{T}}$ & 100 & 1412 & LC435677 & - & - & - & - & - & - \\
\hline 48 & SC074 & Streptomyces spinoverrucosus NBRC $14228^{\mathrm{T}}$ & 98.93 & 1428 & LC435678 & ++ & ++ & + & - & - & \pm \\
\hline 49 & SC191 & Streptomyces spinoverrucosus NBRC $14228^{\mathrm{T}}$ & 99.17 & 1482 & LC435679 & ++ & ++ & ++ & - & - & ++ \\
\hline 50 & SC112 & Streptomyces spiralis NBRC $14215^{\mathrm{T}}$ & 99.01 & 1122 & LC435680 & - & - & \pm & - & - & - \\
\hline 51 & SC006 & Streptomyces spongiae Sp080513SC-24 ${ }^{\mathrm{T}}$ & 98.92 & 1393 & LC435681 & - & _- & - & - & _ & - \\
\hline 52 & SC107 & Streptomyces viridochromogenes NBRC $3113^{\mathrm{T}}$ & 99.36 & 1409 & LC435682 & - & - & ++ & - & \pm & - \\
\hline 53 & SC095 & Streptomyces viridosporus NRRL $2414^{\mathrm{T}}$ & 98.27 & 1487 & LC435683 & ++ & ++ & ++ & - & - & - \\
\hline 54 & SC030 & Streptomyces yogyakartensis NBRC100779 & 99.51 & 1432 & LC435684 & - & - & - & - & - & - \\
\hline 55 & SC076 & Saccharothrix australiensis DSM $43800^{\mathrm{T}}$ & 98.58 & 1414 & LC634111 & ++ & ++ & ++ & ++ & - & ++ \\
\hline
\end{tabular}

"Inhibition area: -, no inhibition area;, $\pm 1-5 \mathrm{~mm}$; +, 6-10 mm; and ++, >10 mm.

Abbreviation: S, Staphylococcus aureus; B, Bacillus subtilis; K, Kocuria rhizophila; E, Escherichia coli; P, Pseudomonas aeruginosa; and C, Candida albicans. 


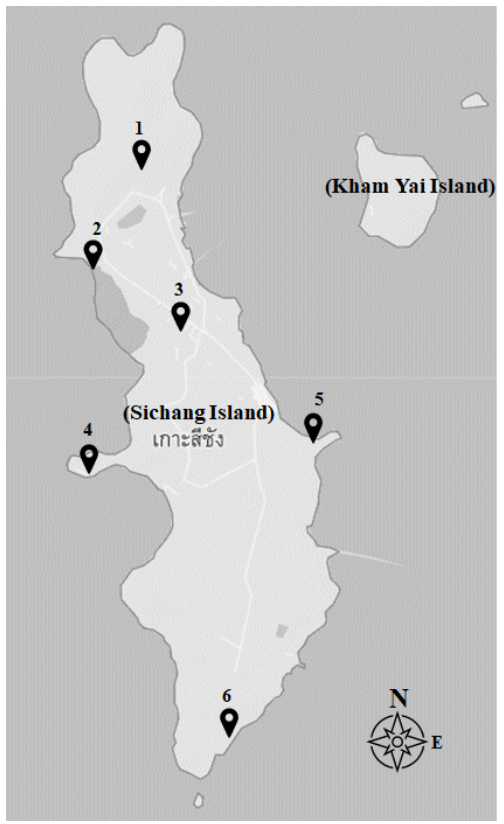

Fig. S1 Sampling site locations on Sichang Island, Chonburi Province, Thailand.

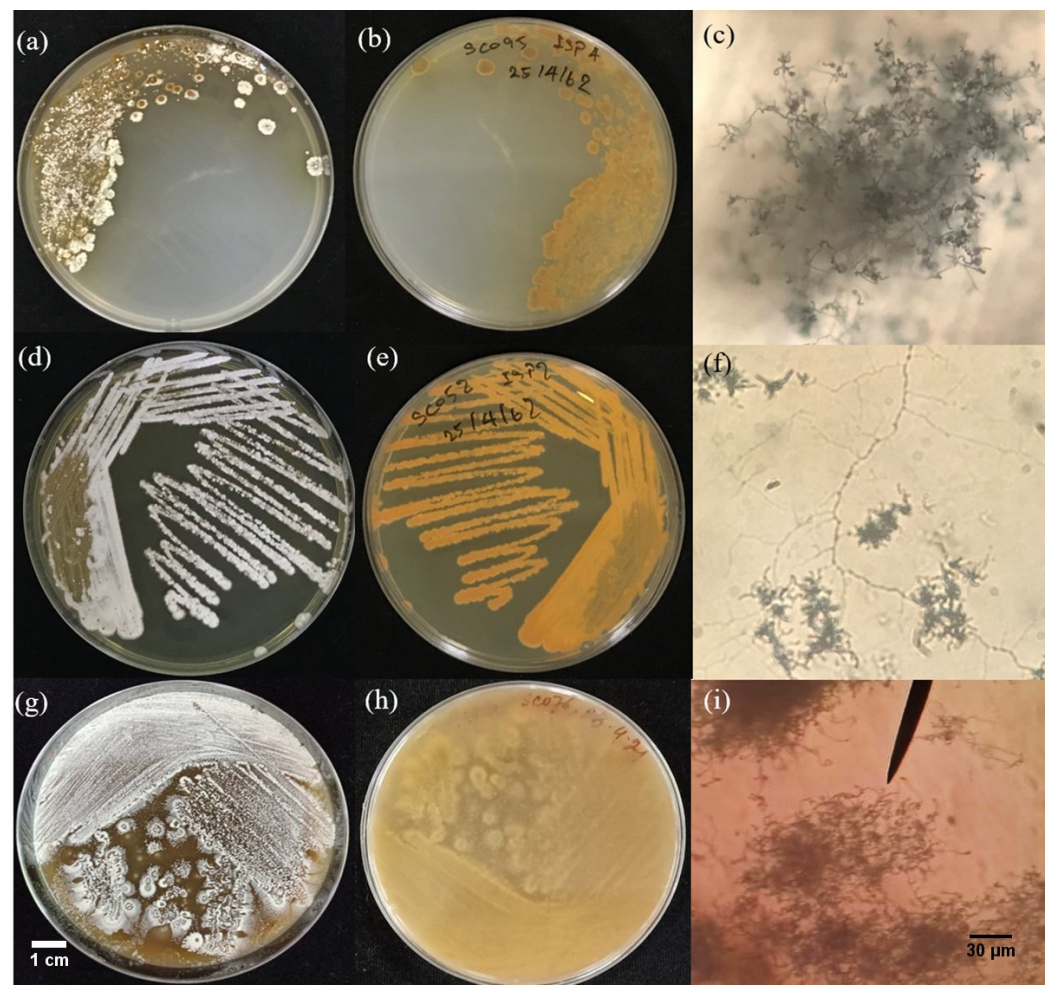

Fig. S2 Cultural characteristics and morphology of representative actinobacteria grown at $30^{\circ} \mathrm{C}$ for 14 days: (a-c), Streptomyces sp. SC095 grown on ISP4 agar; (d-f), Nocardia sp. SC052 grown on ISP2 agar; and (g-i), Saccharothrix sp. SC076 grown on ISP2 agar. The white scale bar $(1 \mathrm{~cm})$ and the black scale bar $(30 \mu \mathrm{m})$ indicate the size of the culture plates and microscopic pictures, respectively. 